\title{
FATO DO PRÍNCIPE OU FORÇA MAIOR-REFLEXOS TRABALHISTAS EM TEMPOS DE COVID 19
}

\author{
Fernanda Silva Doria, Marcio França Teixeira, Luzimar Barreto de França Junior \\ Universidade do Oeste Paulista - UNOESTE, Presidente Prudente, SP. E-mail: fer.silvadoria123@gmail.com
}

\begin{abstract}
Resumo
Em detrimento aos avanços trabalhistas ocorridos durante a fase de reestruturação modernista, faz-se por notório observar que grandes foram as evoluções adquiridas pelas classes operárias. Após várias revoluções e conquistas, os trabalhadores passaram a possuir diversas garantias que foram inseridas na Constituição Federal como absolutas e indisponíveis, a fim de sustentar o equilíbrio pactuado entre empregadores e empregados. Analisando esse cenário e, com o advento do surto endêmico do Novo Coronavírus - COVID 19 , muitos dos direitos formalizados encontram-se "violados", descaracterizando as conquistas adquiridas ao longo da trajetória social do mundo, muitas vezes, coordenada pelo próprio órgão estatal, pelo chamado "Fato do Príncipe". As relações interpessoais foram ligeiramente modificadas e, muitas atividades, suprimidas, a fim de atender as necessidades e formular novos métodos que, com essa conjuntura, sobreveio às populações. Nesse sentido, o projeto em estudo visa examinar quais são os aspectos adotados para a inferência dessa prática, bem como elucidar as particularidades que, em decorrência de tal crise, afetou as classes menos favorecidas pelo sistema. Em aspectos concludentes, analisou-se que o dever de indenizar os empregados pela mitigação das garantias contratuais, nem sempre será responsabilidade integral do empregador; deve-se, no entanto, observar cada caso em concreto, com o objetivo de não desfavorecer de modo excessivo, nenhum dos polos do contrato. À vista disso, para analisar a eficácia e importância dos referidos direitos postergados, considerou-se válida a legislação, jurisprudência e doutrina de diversos autores, com o objetivo de exemplificar os principais efeitos negativos oriundos do poder estatal frente às empresas.
\end{abstract}

Palavras Chave: Avanços Trabalhistas; Revoluções; Direitos Indisponíveis: Fato do Príncipe; Violação.

\section{PRINCE'S FACT OR FORCE MAJEURE-LABOR REFLECTIONS IN TIMES OF COVID 19}

\begin{abstract}
In detriment to the labor advances that took place during the phase of modernist restructuring, it is notorious to observe that great developments were acquired by the working classes. After several revolutions and conquests, workers came to have several guarantees that were included in the Federal Constitution as absolute and unavailable, in order to sustain the balance agreed between employers and employees. Analyzing this scenario and, with the advent of the endemic outbreak of the New Coronavirus COVID 19, many of the formalized rights are "violated", mischaracterizing the achievements acquired throughout the social trajectory of the world, often coordinated by the state agency itself, by the so-called "Prince's Fact". The interpersonal relationships were slightly modified and many activities were suppressed, in order to meet the needs and formulate new methods that, with this situation, came to the populations. In this sense, the project under study aims to examine what are the aspects adopted for the inference of this practice, as well as elucidating the particularities that, as a result of such crisis, affected the less favored classes by the system. In conclusive aspects, it was analyzed that the duty to indemnify employees for the mitigation of guarantees contractual obligations, it will not always be the full responsibility of the employer; however, each specific case must be observed, with the aim of not to disfavor excessively any of the poles of the contract. In view of this, in order to analyze the effectiveness and importance of the aforementioned deferred rights, the legislation, jurisprudence and doctrine of several authors were
\end{abstract}


considered valid, with the objective of exemplifying the main negative effects arising from the state power against companies.

Keywords: Labor Advances; Revolutions; Unavailable Rights: Prince's Suit; Violation

\section{INTRODUÇÃO}

O ano de 2020 restará para sempre marcado pelas mudanças que ocorreram em âmbito mundial. Já nos seus primeiros meses, a deflagração da pandemia do novo Coronavírus, causador da "COVID-19", impôs efetivas alterações em toda a sociedade, alcançando os setores públicos e privados. Como forma de resguardar os direitos mais fundamentais, as autoridades passaram a estabelecer inúmeras regras, umas de alcance somente em empresas, ditadas por seus diretores e proprietários, outras mais gerais, emanadas das autoridades públicas, buscando tutelar, também, o direito à vida da população.

Verifica-se que inúmeras são as consequências das ordens que foram trazidas no cotidiano de toda a sociedade. Aglomerações foram proibidas pelo Poder Público, suspensão de inúmeras atividades, tais como: academias, jogos esportivos, utilização de parques e demais bens de uso comum do povo, estabelecimentos comerciais tiveram suas atividades suspensas, ingressos aos Shoppings foram vetados, aulas presenciais foram suspensas; ou seja, obrigatoriamente, se impôs uma adequação e classificação das atividades em essenciais e/ou não essenciais, com base nas necessidades primárias dos cidadãos.

De toda sorte a população, de modo geral, entrou em contato direto com termos que até então eram desconhecidos da grande maioria, como: o Poder de Império, ato administrativo, fato do príncipe e força maior. Nesse contexto, este trabalho possui por escopo analisar as formas pelas quais essa vontade administrativa impõe consequências no cotidiano das relações de trabalho, seus efeitos e permissivos legais.

\section{DELINEAMENTO METODOLÓGICO}

A ordenação aplicada será o método dedutivo, emanando de uma generalização para uma questão mais particularizada.

Segundo Gil (2008), este meio de pesquisa parte de princípios reconhecidos como verdadeiros e indiscutíveis, possibilitando chegar a conclusões em virtude unicamente de sua lógica. É o segmento proposto pelos racionalistas, segundo os quais só a razão é capaz de levar ao conhecimento verdadeiro, que decorre de princípios a priori evidentes e irrecusáveis. A abordagem define-se pela hermenêuticodialética. A hermenêutica pode ser considerada como uma técnica que compreende textos, em sentido amplo: biografia, livro, artigo, narrativa, documento, pareceres, legislações, jurisprudências, teses e dissertações. Por sua vez, a abordagem dialética procura nos fatos os núcleos obscuros e contraditórios, para realizar críticas em relação aos mesmos. $O$ pensamento dialético compreende que a análise dos significados deve ser realizada, considerando as práticas sociais e ressaltando o condicionamento histórico das falas (MINAYO, 2010).

\section{RESULTADOS}

\section{Estado e Seu Poder Regulamentar}

O Direito Administrativo moderno traça uma série de princípios e características que devem ser inerentes a Administração Pública para o aperfeiçoamento de seu papel. Podemos destacar a Supremacia do Interesse Público, a Presunção de Legitimidade do Ato Administrativo, a Cautela Administrativa, o Poder de Império, tudo, dentro dos limites do Estado Constitucional de Direito. A Carta Magna revela ainda que compete ao chefe do poder executivo a disponibilidade para editar e promover a criação de normas e decretos, com o objetivo de positivar suas decisões em face de sua autonomia jurídica e por meio de atos administrativos, a fim de considerá-lo garantidor das relações entre pessoas naturais e empresariais, de modo a complementar e detalhar as leis, para que se possa alcançar a proteção dos direitos e o bem estar de todos os cidadãos.

De acordo com a competência do poder executivo, elenca o artigo 84 da Constituição Federal que:

Compete privativamente ao Presidente da República: I- nomear e 
exonerar os Ministros de Estado; II - exercer, com o auxílio dos Ministros de Estado, a direção superior da administração federal; III - iniciar o processo legislativo, na forma e nos casos previstos nesta Constituição; IV -

sancionar, promulgar e fazer publicar as leis, bem como expedir decretos e regulamentos para sua fiel execução. (BRASIL, 1988, Art. 84)

O Poder Regulamentar representa uma prerrogativa de direito público, pois que conferido aos órgãos que tem a incumbência de gestão dos interesses públicos (CARVALHO FILHO, 2020, p.70).

Constata-se que, nos últimos meses, em função da pandemia, nunca ficou tão em evidência o Poder do Estado em regulamentar, como busca do interesse da coletividade, situações que outrora não eram regulamentadas (ou pensadas), impondo efeitos e consequências sobre toda a sociedade.

\section{Os Atos Administrativos}

Como forma de alcançar a intenção da Administração Pública e dar efetividade ao seu Poder Regulamentar, o Estado pratica uma série de ações, manifestando sua vontade amparada por sua competência e em obediência, sempre, aos princípios informados no caput do artigo 37 da Constituição, a saber: legalidade, impessoalidade, moralidade, publicidade e eficiência. Referidos atos irão produzir efeitos jurídicos, a fim de alcançar os seus administrados, visando sempre o interesse público. (CARVALHO FILHO, 2020, p. 25).

Os atos administrativos podem ser ainda vinculados ou discricionários. $\mathrm{O}$ ato vinculado é aquele em que diante do comando legal e da hipótese fática o administrador está obrigado a conceder ao administrado o requerido e estabelecido pela lei (MARINELA, 2012, p. 262). Em outras palavras, é o ato praticado não apenas nos limites da lei, mas conforme os seus comandos, pois não haverá opção ao administrador (MARINELA, 2012, p. 262).

$\mathrm{O}$ ato discricionário, por outro lado, prega justamente o oposto. Nele, a lei possibilita ao administrador mais de um comportamento possível de ser adotado diante de um caso concreto (MARINELA, 2012, p. 262).

É certo que a produção de regras pela Administração Pública, disciplinando a sociedade, implica também em consequências. Neste conjunto de regras e consequências jurídicas a elas relacionadas, encontra-se o que conhecemos como Fato do Príncipe.

O Fato do Príncipe caracteriza-se pela possibilidade que o poder público possui de adotar e influir em medidas que poderão impactar os contratos que foram realizados entre particulares ou com a administração, retardando ou impedindo sua execução, para assegurar determinações emergências como, por exemplo, no enfrentamento a Pandemia do Novo Coronavírus (COVID-19). Nesse sentido, Celso Antônio Bandeira de Mello define tal teoria como sendo um "agravo econômico resultante de medida tomada sob titulação diversa da contratual, isto é, no exercício de outra competência, cujo desempenho vem a ter repercussão direta na econômica contratual estabelecida na avença". (MELLO, 2009.)

Necessário ainda destacar que parte da doutrina administrativa impõe para a configuração do Fato do Príncipe (ou factum principis) que esta modalidade atinge apenas àqueles que contratam perante a Administração Pública, ou seja, que a iniciativa dos poderes públicos torne mais onerosa a situação daquele que estabelece contratos administrativos apenas. (HARIOU, 1927)

Em decorrência das restrições impostas para o enfrentamento da pandemia do novo Coronavírus, as relações laborais tiveram impacto profundo, tornando-se excessivamente onerosos aos empregadores. Fôsse contratos de natureza civil, a Teoria da Imprevisão poderia ser invocada para a solução dos problemas advindos, todavia, há limites teleológicos e legais para a absorção desta teoria dentro da seara trabalhista.

Não por outra razão, o caput do Artigo 2.a da Consolidação das Leis do Trabalho ilustra que:

Considera-se empregador a empresa, individual ou coletiva, que, assumindo os riscos da atividade econômica, admite, assalaria e dirige a prestação pessoal de serviço. § 1ㅇ - Equiparamse ao empregador, para os efeitos exclusivos da 
relação de emprego, os profissionais liberais, as instituições de beneficência, as associações recreativas ou outras instituições sem fins lucrativos, que admitirem trabalhadores como empregados. $\S$ 2o Sempre que uma ou mais empresas, tendo, embora, cada uma delas, personalidade jurídica própria, estiverem sob a direção, controle ou administração de outra, ou ainda quando, mesmo guardando cada uma sua autonomia, integrem grupo econômico, serão responsáveis

solidariamente pelas obrigações decorrentes da relação de emprego. § 3 Não caracteriza grupo econômico a mera identidade de sócios, sendo necessárias, para a configuração do grupo, a demonstração do interesse integrado, a efetiva comunhão de interesses e a atuação conjunta das empresas dele integrantes. (BRASIL, 1943, Art. 2\%).

Assim, empregador é aquele que assume os riscos da atividade econômica, se assim o é, a ele cabem todas as consequências de sua atividade. Ocorre que a dúvida persiste justamente porque as medidas restritivas e prejuízos experimentados foram causados a partir de atos administrativos.

O Estado possui, por óbvio, a titularidade e competência para ordenar a suspensão de qualquer tipo de atividade econômica (ou não) com o propósito de manter e suscitar a boa ordem e funcionamento da sociedade, ainda que em período de normalidade (ou não), com base em seu Poder Regulamentar e na busca pelo bem comum.

Partindo dessa premissa, a Consolidação das Leis do Trabalho, em seu artigo 486, faz menção às consequências decorrentes do Fato do Príncipe:
No caso de paralisação temporária ou definitiva do trabalho, motivada por ato de autoridade municipal, estadual ou federal, ou pela promulgação de lei ou resolução que impossibilite a continuação da atividade, prevalecerá o pagamento de indenização, que ficará a cargo do governo responsável. (BRASIL, 1943, Art. 486).

Desse modo, seria possível observar que - artigo supracitado perfaz a ideia de "indenização" pelas relações trabalhistas afetadas; não suprindo, na maioria das vezes, o percentual necessário para erradicar as consequências que as determinações Estatais influenciarão nos regimes contratuais trabalhistas. Mas, para quem ficará o ônus decorrente dos atos praticados pelo Estado?

Nesse cenário, para que aconteça o fenômeno "factum principis", associado com o dever da indenização por parte do Estado, seria necessário que não sobreviesse a paralisação das atividades estatais, pois acenderia o risco para com os empregadores.

De acordo com o entendimento do Ministro do Superior Tribunal de Justiça Sérgio Kukina, na qual expõe sua argumentação em um debate transmitido pela TV ConJur com o tema "As regras emergenciais em tempos de Covid19 ", relata que:

A discussão jurídica vai
passar pelo aferimento da
razoabilidader e
proporcionalidade das
ações do governo. Por
isso, não há como
determinar fórmula de
ação: o fato concreto vai
nortear a análise.

Em outra via, também, o Poder Público terá de ser responsabilizado pela simples determinação de encerramento das atividades laborais, tornando contestável a subsistência das atividades trabalhistas. Porém, diante do estado de calamidade pública, seria o Estado responsável pelas determinações a fim de assegurar a boa ordem e o bem-estar social? 
Com relação ao debate apontado alhures, a Advogada Roberta Rangel aponta que:

A conceituação dos fatos que a sociedade irá viver e já está vivendo, é muito complexa. Diferenciar o que seja fato do príncipe, força maior ou caso fortuito, hipótese da teoria da imprevisão ou simples hipótese de reajuste de prestações devem ser questões muito discutidas.

É necessário, contudo, que a sociedade se atente a algumas questões de ordem legal. A primeira, diz respeito ao Estado de Calamidade reconhecido pelo parágrafo único do artigo 1.ㅇ da MP 927/2020, cujo parágrafo único esvazia a tese do factum principis ao informar que as medidas restritivas tomadas durante a pandemia constituiriam hipóteses de força maior:

Art. 10 Esta Medida

Provisória dispõe sobre as medidas trabalhistas que poderão ser adotadas pelos empregadores para preservação do emprego e da renda e para enfrentamento do estado de calamidade pública reconhecido pelo Decreto Legislativo $n=6$, de 20 de março de 2020, e da emergência de saúde pública de importância internacional decorrente do coronavírus (covid-19), decretada pelo Ministro de Estado da Saúde, em 3 de fevereiro de 2020, nos termos do disposto na Lei no 13.979 , de 6 de fevereiro de 2020. Parágrafo único. $\mathrm{O}$ disposto nesta Medida Provisória se aplica durante o estado de calamidade pública reconhecido pelo Decreto Legislativo no 6, de 2020,e, para fins trabalhistas, constitui hipótese de força maior, nos termos do disposto no art. 501 da Consolidação das Leis do Trabalho, aprovada pelo Decreto-Lei no 5.452, de 10 de maio de 1943. (BRASIL, 2020).

O artigo 501 da Consolidação das Leis do Trabalho pressupõe:

Entende-se como força maior todo acontecimento inevitável, em relação à vontade do empregador, e para a realização do qual este não concorreu, direta ou indiretamente. $\S \mathbf{1}$ - A imprevidência do empregador exclui a razão de força maior. § $2 \mathbf{0}$ - À ocorrência do motivo de força maior que não afetar substancialmente, nem for suscetível de afetar, em tais condições, a situação econômica e financeira da empresa não se aplicam as restrições desta Lei referentes ao disposto neste Capítulo. (BRASIL, 1943, Art. 501).

Desse modo, restaria afastada a solução indenizatória proposta no artigo 486 celetista, abrindo-se possibilidade, todavia, as possibilidades de mitigação propostas pelos artigos 502 e 503 da CLT:

Art. 502 - Ocorrendo motivo de força maior que determine a extinção da empresa, ou de um dos estabelecimentos em que trabalhe o empregado, é assegurada a este, quando despedido, uma indenização na forma seguinte: I - sendo estável, nos termos dos arts. 477 e 478; II - não tendo direito à estabilidade, metade da que seria devida em caso de rescisão sem justa causa; III - havendo contrato por prazo determinado, aquela a que se refere o art. 479 desta Lei, reduzida igualmente à metade. (BRASIL, 1943, Art. 502).

Art. 503 - É lícita, em caso de força maior ou 
prejuízos devidamente comprovados, a redução geral dos salários dos empregados da empresa, proporcionalmente aos salários de cada um, não podendo, entretanto, ser superior a $25 \%$ (vinte e cinco por cento), respeitado, em qualquer caso, o salário mínimo da região.

Parágrafo único - Cessados os efeitos decorrentes do motivo de força maior, é garantido restabelecimento dos salários reduzidos. (BRASIL, 1943, Art. 503).

Assim sendo, a responsabilização para com a parte passiva da relação contratual nem sempre será remida de forma absoluta pela empresa - empregadores; devendo assim, ser observadas as espécies que vulgarizam o "cumprimento parcial" de tais verbas indenizatórias.

\section{Alterações dos Contratos de Trabalho e Pandemia}

Segundo o Instituto Brasileiro de Geografia e Estatística (IBGE, 2020) a taxa de desemprego correlacionada ao COVID-19 fez com que $o$ índice de inatividade ensejasse em alterações significativas ao tempo de alcance da pandemia. Nesse aspecto, a taxa de desemprego elevou-se em relação ao período de implemento das medidas de isolamento social que foram adotadas (conforme determinação governamental), provocando grandes alterações nos índices de empregos formais.

O alargamento nos casos de desemprego e as alterações relativas aos trabalhos formais, segundo os dados do Cadastro Geral de Empregados e Desempregados - CAGED. (Brasília: MTE, 2010. Pessoal), pôde retratar os reflexos que, por meio de medidas e decretos, foram adotados; a exemplo do isolamento social - de modo a ser uma forma inicial de atenuar os índices de pessoas infectadas pelo COVID-19. À vista disso, verificou-se decréscimos contundentes na economia do país, de modo a motivar os aumentos nas taxas de inatividade e as modificações nos contratos trabalhistas.
A Lei 13.979 de 2020, em seu art.3o, trata de alguns conceitos específicos que teve de ser realizados, tais como: quarentena e isolamento. No parágrafo 3a do referido artigo, a lei confere ao empregado, dentre outras faculdades, o direito de faltar do serviço em razão dos aspectos supra, sendo-as consideradas como "faltas justificadas", ou seja, não possibilitará o desconto na folha de pagamento dos trabalhadores.

Conforme exteriorizado, o Artigo 3 da Lei 13.979 de 2020 elenca que:

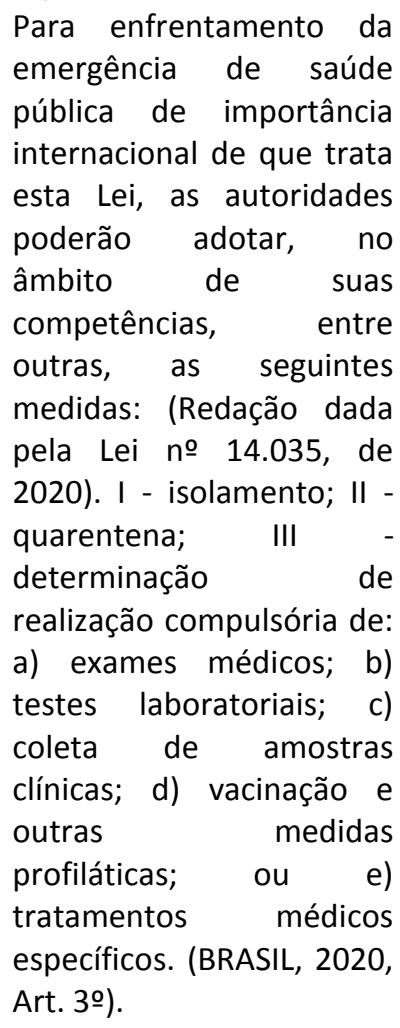

Os panoramas trabalhistas e as jornadas de atividade empregatícias tiveram de se flexibilizar em decorrência da crise que, cada vez mais, se abatia sobre os trabalhadores e empresas, a fim de manter os contratos que foram estabelecidos antes do infortúnio. Nesse aspecto, com o reconhecimento do estado de "Calamidade Pública" deferida pelo Governo Federal, foram implantadas, no cenário jurídico nacional, Medidas Provisórias (MPs), com o intento de permitir acordos em contratos de trabalho diretamente entre empresas e seus trabalhadores.

Nesse sentido, a MP no 927, de 22 de março de 2020, trouxe medidas para a preservação do emprego e da renda. As jornadas de trabalho, antes de forma presencial, puderam ser transferidas para a realização de forma remota (on line), evitando a aglomeração e circulação de pessoas, como forma preventiva à 
transmissão do vírus. A mudança do local de execução das tarefas, teve de ser comunicada ao colaborador com antecedência mínima de 48 (quarenta e oito) horas. Referida alteração alcançaram também estagiários e aprendizes.

Outra questão tratada pela MP no 927 foi relativa à antecipação de férias, devendo esta ser notificada aos colaboradores com o mínimo de 48 horas, de forma escrita ou por meio eletrônico de visualização, estando de comum acordo entre as partes. Desse modo, não poderá ser concedido o recesso laboral, tendo prazo inferior a cinco dias consecutivos, apresentando como preferenciais os funcionários que se incluem no grupo de risco do coronavírus (COVID-19), para tal concessão.

A possibilidade de concessão de férias coletivas também foi indicada pela MP no 927, podendo a empresa ao conceder férias coletivas para o conjunto de empregados, informá-los com o mínimo de 48 horas, não ultrapassando os limites mínimos e máximos que a Consolidação das Leis do Trabalho estabelece.

A MP $\mathrm{n}$ - 927, buscando ser instrumento de manutenção das relações trabalhistas, tratou também de outros pontos fundamentais para amenizar as consequências econômicas deletérias tanto doo empregador quanto do empregado. Possibilitou o aproveitamento e antecipação de feriados, a utilização de banco de horas, suspensão de exames médicos ocupacionais e, também, dentre outras normatizações, previu a suspensão do pagamento do FGTS para as competências de abril, maio e junho de 2020.

Outra medida emergencial trazida pelo Governo Federal foi a MP no 936, que foi constituída com o intuito de reduzir as jornadas de trabalho ou, como alternativa, suspender as relações contratuais que foram firmadas. Dentre as possibilidades trazidas pela MP 936, destacase a de redução de jornada e a redução de salários.

As alterações nas jornadas de trabalho poderão ser efetuadas sob a margem de $25 \%$, $50 \%$ e $70 \%$ do valor real e anteriormente estabelecido. Sendo também objeto de mudança o salário que, de forma proporcional terá a referida redução, precisando esse ser restabelecido em até 90 dias a contar do término do estado de calamidade pública. A suspensão temporária dos contratos trabalhistas também foi normatizada pela MP no 936, podendo o empregador acordar a suspensão do contrato de trabalho pelo prazo máximo de 60 (sessenta) dias.

\section{Perspectivas das Retomadas das Relações Trabalhistas - Empregabilidade}

A decretação por parte do Estado de medidas e conjunturas estruturais de isolamento conseguiu, de modo eficaz, desacelerar a disseminação do vírus (COVID-19), muito além de panoramas nacionais. Porém, de outro modo, tais deliberações influenciaram de modo direto nas perspectivas econômicas laborais e nos programas de empregabilidade, fazendo com que as atividades que não possuem vínculo formal (trabalho autônomo), se ampliem cada vez mais, cuja taxa atualmente é estimada em 24\%, conforme estudo da Federação de Comércio de Bens do Estado de São Paulo - FECOMÉRCIO/SP, em entrevista à "UM BRASIL".

Ao que parece, a dinâmica do trabalho adotada pelo governo frente às entidades empresariais, com o escopo de minorar as consequências e efeitos da pandemia, não se mostrou seguramente útil e significativa. Conforme posicionamento do Professor José Pastore na mencionada entrevista, a retomada dos empregos em decorrência do retraimento social, somada com os índices de desigualdade e desemprego que anteriormente alarmava, ocasionará uma "depressão econômica" ainda maior entre a população brasileira, visto que não é possível calcular com exatidão, as margens e curvas de alcance do Coronavírus.

Nesse aspecto, identifica-se que quanto maior for a escala de atingimento do vírus, maior será o tempo de reestruturação da economia e do mercado de trabalho, possuindo garantia (ainda que reduzida), somente a parcela que possui vínculo empregatício com alguma entidade empresarial A outra parte, porém, não será atingida pelas medidas de manutenção dos trabalhos remotos, suspensão temporária ou redução das jornadas de trabalho, como enumera as medidas provisórias 927/2020 e 936/2020, mencionada alhures.

De forma redundante, o período "póspandemia" não pode ser considerado como um consolo econômico para os trabalhadores e empregadores, pois restará por um bom tempo a ameaça nas relações laborais. É evidente e imperiosa a necessidade de programas públicos para a consertação do estado de desigualdade que restará no mercado de trabalho e junto aos trabalhadores e empregadores. 


\section{CONSIDERAÇÕES FINAIS}

A partir dos estudos e análises realizadas e em conformidade com os aspectos que norteiam a Administração Pública, foi possível verificar que as manifestações do poder público trouxeram fortes consequências para os administrados, e deforma mais severa, nos primeiros meses do ano de 2020. As determinações da Administração Pública com o objetivo de fechar provisoriamente estabelecimentos de menor utilidade/conveniência como bares, restaurantes, lojas e shoppings, impactaram diretamente os contratos trabalhistas e a rotina de empregados e empregadores. Todavia, a nosso ver e por expressa previsão legal, as medidas tomadas poderão, quando muito, ensejar em hipótese de Força Maior a justificar a adoção das medidas legais dos artigos 501 e seguintes da CLT, mas não a indenização como se Factum Principiis fosse nos termos do artigo 486 celetista.

Da mesma forma restou evidenciado que as medidas sanitárias tomadas pela Administração Pública tiveram sempre a intenção de resguardar um bem maior, qual seja, a manutenção da própria vida dos cidadãos e permitir o enfrentamento, de forma controlada, dos efeitos da pandemia do novo Coronavírus. Não havia, portanto, a nosso ver e diante das evidências, outra forma de atendimento, inclusive, porque tais medidas foram tomadas em escala mundial.

Fica claro que os atos praticados pelos chefes do Poder Executivo, independente da esfera, trouxeram consequências para todos, sentidas em maior escala nesse momento de pandemia. Diante das mudanças implementadas pelo governo, decorrentes do poder regulamentar, verifica-se a rápida ação dos próprios entes, no sentido de minorar os efeitos nocivos nas relações trabalhistas.

A figura do Teletrabalho, já trazida na Reforma Trabalhista de 2017, foi amplamente difundida, virando quase que regra nos contratos de trabalhos, tendo a alteração do cumprimento das jornadas, tratada pela MP no 927, que, ao final de seu período de efeitos, não teve prorrogação, não sendo também convertida em lei.

Outra sorte teve a MP no 936, que instituía um plano emergencial de manutenção de emprego e renda, sendo convertida na Lei no 14.022, de 06 de julho de 2020, de modo a trazer diretrizes e normas, a fim de buscar o reequilíbrio das relações

que envolvem

OS empregados/empregadores.

Diante de todo cenário de imprevisão que surgiu e de todas as mudanças que foram produzidas, verificamos que somente com ajustes e readequações poderemos continuar a seguir com a manutenção e implementação de novos contratos trabalhistas (ou não) que foram iniciados antes da fase de pandemia, e que a capacidade de superação e adaptação, mais do que nunca,dependerá, além de grandes esforços da sociedade, de uma atuação robusta da Administração Pública no enfrentamento dos reflexos negativos da pandemia.

\section{REFERÊNCIAS}

BRASIL. Constituição (1988). Constituição da República Federativa do Brasil de 1988.

BRASIL. Presidência da República, (2020). Disponível

em:

http://www4.planalto.gov.br/legislacao. Acesso em: 09 jul. 2020.

BRASIL. Decreto-lei no 5.452, de 1 de maio de 1943. Aprova a consolidação das leis do trabalho. Lex: coletânea de legislação: edição federal, São Paulo, v.

BRASIL. Lei no 13.979 de 06 de fevereiro de 2020. Dispõe sobre as medidas para enfrentamento da emergência de saúde pública de importância internacional decorrente do coronavírus responsável pelo surto de 2019.Legislação Complementar. p.01.

BRASIL. Lei no 14.020 de 07 de julho de 2020 . Dispõe sobre o Programa Emergencial de Manutenção de Emprego e de Renda. Legislação Complementar. p.01.

BRASIL. Presidência da República. SecretariaGeral. Subchefia para Assuntos Jurídicos. Medida Provisória Medida Provisória N`927 de 22 de Março de 2020. Dispõe sobre as medidas trabalhistas para enfrentamento do estado de calamidade pública reconhecido pelo Decreto Legislativo no 6 , de 20 de março de 2020, e da emergência de saúde pública de importância internacional decorrente do coronavírus (covid19), e dá outras providências. Disponível em: http://www.planalto.gov.br/ccivil_03/_ato20192022/2020/Mpv/mpv927.htm. Acesso em: 11 de Julho de 2020. 
CAGED. Cadastro Geral de Empregados e Desempregados. Disponível em: http://portalfat.mte.gov.br/programas-e-acoes2/caged-3/ Acesso em: 11 jul. 2020.

CARVALHO FILHO, J. S. Manual de direito administrativo. 34. ed.SãoPaulo: Atlas, 2020.

DI PIETRO, M. S. Z. Direito Administrativo. 25. ed. São Paulo: Atlas, 2012.

FECOMERCIO-SP. Economia e Legislação. Disponível em https://www.fecomercio.com.br/noticias/econo mia/brasil. Acesso em: 11 jul. 2020.

FOLHA DE SÃO PAULO. Desemprego aumentou em todas as regiões do Brasil com avanço do coronavírus. Disponível em: https://www1.folha.uol.com.br/mercado/2020/0 5/desemprego-aumentou-em-12-estados-comavanco-do-coronavírus.shtml. Acesso em: 09 jul. 2020.

IBET. INSTITUTO BRASILEIRO DE ESTUDOS ONLINE. Disponível em: https://www.ibet.com.br/ Acesso em: 11 jul. 2020.

GIL, A. C. Métodos e Técnicas de Pesquisa Social. 6. ed. São Paulo: Atlas,2008.

IBGE.INSTITUTO BRASILEIRO DE GEOGRAFIA E ESTATÍ́sTICA. Censo Brasileiro de 2020. Estatísticas Sociais. IBGE, 2020.

HAURIOU, M. Précis de Droit Administratif. 11.ed., 1927.

MARINELA, F.. Direito Administrativo. 6. ed. Niterói: Impetus, 2012.

YOUTUBE, 4 de Maio de 2020. Disponível em: http://www.fecomercio.com.br/public/umbrasil/materias/protecoes-trabalhistas-tem-deser-direcionadas-as-pessoas-e-nao-aosempregos. Acesso em: 03 ago. 2021.

MELLO, C. A. B. Curso de Direito Administrativo. 27. ed. São Paulo: Malheiros Editores, 2010.

MINAYO, M. C. S.. Pesquisa Social. 26. ed. Petrópolis-RJ: Vozes, 2007. 